Revista Iberoamericana. Vol. LXIV, Núms. 182-183, Enero-Junio 1998; 271-286

\title{
LAS ÁGILES MUSAS DE LA MODERNIDAD: PATRÍCIA GALVÃO Y NORAH LANGE
}

\author{
POR \\ VICKY UNRUH \\ University of Kansas
}

\begin{abstract}
A primera vista, Pagú - la "nueva mujer" antropofágica—y Norah —la "walkyria" del ultraísmo - aparentan más diferencias que terreno común. Patrícia Galvão (Brasil, 1910-1962) escribió poemas, una novela "proletaria" experimental y otra en colaboración, y crítica periodística sobre temas culturales.' Entre 1928 y 1940, se destacó por la rebeldía ante toda convención social y el activismo de izquierda, por el cual sufrió encarcelamiento y tortura. Norah Lange (Argentina, 1906-1972), autora de tres libros de poesía, seis obras en prosa, y una colección de discursos, ${ }^{2}$ rehuyó la literatura comprometida y, a despecho de su activismo estético, su relación con la vida cotidiana fue generalmente menos contenciosa que la de Galvão. Los proyectos culturales de estas dos escritoras durante los años veinte y treinta, sin embargo, ejemplifican de modo comparable la paradójica relación de mujeres con las vanguardias latinoamericanas y su retórica de la modernidad estética y cultural. No obstante las valiosas diferencias contextuales, el modelo comparativo ha sido fructífero para el estudio crítico de las metas estéticas, las revisiones del papel del artista, y los encuentros entre la especificidad cultural y la modernidad en los movimientos de vanguardia en Brasil e Hispanoamérica. ${ }^{3}$ De un modo análogo, el estudio comparativo de las mujeres
\end{abstract}

\footnotetext{
${ }^{1}$ Las novelas de Galvão incluyen Parque Industrial (1933) y A famosa revista (1945), escrita con Geraldo Ferraz. La antología de obra creativa y crítica, Pagú-Vida-Obra, publicada en 1982 por Augusto de Campos, contiene selecciones de su poesía, previamente inédita, y de su crítica social y artística publicada en periódicos durante los años cuarenta y cincuenta. Esta colección también reproduce sus columnas, "A mulher do povo", publicadas en 1931 en la revista $O$ Homem do Povo, redactada por Oswald de Andrade.

${ }^{2}$ Las obras poéticas de Lange incluyen La calle de la tarde (1925), Los dias y las noches (1926), y El rumbo de la rosa (1930). Sus obras en prosa incluyen Voz de la vida (1927), 45 dias y 30 marineros (1933), Cuadernos de infancia (1937), Antes que mueran (1944), Personas en la sala (1950), y Los dos retratos (1956). Publicó la colección Discursos en 1942, y subsiguientes ediciones ampliadas llevan el título Estimados cóngeres.

${ }^{3}$ Las aproximaciones comparativas a las vanguardias hispanoamericanas y brasileñas incluyen los trabajos de Forster, Müller-Bergh, Schwartz, y Unruh, entre otros.
} 
ligadas de algún modo a las vanguardias ilumina la comprensión de cómo estas escritoras se manejaban en un ambiente literario esencialmente masculino para desarrollar sus propios proyectos culturales.

En este contexto, lo compartido entre Galvão y Lange sobrepasa las divergencias. Las dos fueron figuras centrales en las actividades de renombrados grupos vanguardistas de la época: Galvão con el círculo de la Revista de Antropofagia (1928-29) de São Paulo, y Lange con los generadores de Prisma (1921-22), Proa (1922-23; 1924-26), y Martín Fierro (1924-27) en Buenos Aires. Las dos mujeres sostuvieron estrechos lazos personales con líderes de los grupos: Oswald de Andrade, compañero de Galvão y su esposo entre 1930 y 1935, y Oliverio Girondo, compañero de Lange y su esposo desde 1943 hasta la muerte de Girondo en 1967. Cada mujer fue denominada explícitamente la musa de su círculo. Este papel abarcaba no sólo las reiteradas alabanzas de los socios masculinos, sino también una asignada identidad como la palpable encarnación de la innovadora actitud estética del grupo. Cada mujer desempeñó su papel de musa con suma pero paradójica creatividad. Por una parte, abrazaron con energía y aparente entusiasmo el asignado rol, especialmente en el aspecto performativo y corporal que constituía la figura femenina como una manifestación visual de los deseos de un implícito público masculino. ${ }^{4} \mathrm{~A}$ partir de esta aparente apropiación de los códigos de género sexual vigentes, sin embargo, cada escritora realizó una indagación crítica sobre su rol de musa, elaborándola en función de su propio proyecto estético-cultural y otorgándole su propio carácter.

Hija de dioses, la musa de la tradición clásica era una figura femenina de gran belleza y destreza creativa propia. El artista la invocaba como fuente de inspiración y repositorio de sabiduría. En distintas épocas históricas, la musa experimentaba pertinentes transformaciones ideológicas. Así la Beatriz de Dante proveía, además de inspiración estética, la promesa de la salvación espiritual por vía del amor idealizado. Las musas invocadas por los profanos movimientos internacionales de vanguardias paradójicamente encarnaban tanto las gastadas fórmulas estéticas bajo ataque como los alternativos principios estéticos de la modernidad. Con mordaz misoginia, el futurismo atacaba a las mujeres inspiradoras del lacrimoso verso romántico. Los surrealistas proyectaban sobre la imagen femenina en la modernidad no sólo la pérdida de aura ${ }^{5}$ de la mujer-fragmento (Caws, "Ladies") sino también la anhelada recuperación del aura en la mujer del enigma perseguido, del encuentro fortuito, o de la inocencia recuperada en la niñez o la locura. ${ }^{6}$ En Latinoamérica, el género sexual infiltraba la retórica

\footnotetext{
${ }^{4}$ Para el estudio del explícito papel de la performance en las actividades culturales de una mujer de las vanguardias latinoamericanas, ver mi artículo "Una equívoca Eva moderna: Performance y pesquisa en el proyecto cultural de Antonieta Rivas Mercado".

${ }^{5}$ El concepto de aura empleado aquí es, evidentemente, el de Walter Benjamin en "The Work of Art in the Age of Mechanical Reproduction".

${ }^{6}$ Para una serie de indagaciones perspicaces sobre las representaciones surrealistas de la mujer, ver la colección de Caws, Kuenzli y Raaberg, Surrealism and Women.
} 
vanguardista que generalmente les atribuía potencia "viril" a los vanguardistas y afeminamiento a los tradicionales, aunque en México los términos se invirtieron.? Ante el bombardeo de las imágenes en los medios de comunicación de masas de las flappers, las estrellas de Hollywood y las feministas anglo-americanas, los vanguardistas en Latinoamérica construían musas modernas, como la "Eva ativa ... dançando o tango e datilografando uma conta corrente" de los modernistas brasileños (Picchia 291) o La Señorita Etc. de los estridentistas mexicanos, con sus "pasos armoniosos, cronométricos de fox-trots" (Vela 67). Dentro de este ámbito cultural, las musas de carne y hueso rastreaban sus propios caminos.

Normalista de familia burguesa, Patrícia Galvão entró al círculo antropofágico en 1928 gracias a su amistad con la pintora Tarsila do Amaral, la esposa y musa previa de Oswald de Andrade. ${ }^{8}$ Galvão, declamadora de poesía, publicó dibujos en la Revista de Antropofagia. La crítica reciente la ha venerado como la encarnación del espíritu de su época: "el símbolo más esencial de todo lo nuevo, lo revolucionario, y lo peligroso" (Besse 103), la "nueva mujer brasileña de la era modernista" (Bloch 188), una "musa inspiradora" (Teixeira Furlani 8), o la "musa revolucionaria del modernismo brasileño" (Jackson 117). ${ }^{9}$ Los orígenes de esta caracterización se encuentran en los acontecimientos de su época. En 1928, el poeta y antropófago Raul Bopp le otorgó a Galvão el apodo Pagú y celebró su figura y "olhos moles" en el poema "Coco de Pagú", publicado en la Revista Para Todos: "Toda gente fica olhando / seu corpinho de vai-e-vem / umbilical e molengo / de não-sei-o-que-é-que-tem" (de Campos s.n.). En los mismos años, dos dibujos de Galvão por Emilio di Cavalcanti, publicados en la Revista Para Todos la representan precisamente como la yuxtaposición entre lo primitivo y lo moderno que caracterizaba la estética antropofágica. Así el dibujo que acompaña el poema de Bopp la construye como una mujer sencilla y voluptuosa, tocando la guitarra y rodeada de cactos y casitas humildes evocadoras de los cuadros primitivistas de Tarsila. En el otro, aparece como la "nueva mujer" a-la-flapper, exageradamente maquillada, con vestido corto y boquilla. Un anexo comentario de Álvaro Moreyra sobre esta imagen destaca la originalidad y el anti-racionalismo, rasgos típicos de la antropofagia: "Pagú aboliu a grammática da vida. ... Pagú não tem modos. Tem gênio" (Campos). ${ }^{10}$

\footnotetext{
${ }^{7}$ En México de los años veinte, se desarrolló una polémica que caracterizaba la literatura de especifidad cultural mexicana como "viril" y las innovaciones que hoy en día se asocian con el grupo Contemporáneo como "afeminadas". Para los detalles de este debate, ver Díaz Arciniega. ${ }^{8}$ Para recientes análisis de la vida y obra de Galvão, ver los estudios de Besse, Bloch, de Campos, y Jackson, además de mi artículo "¿De quién es esta historia?: La narrativa de vanguardias en Latinoamérica", que incluye un análisis de Parque Industrial como un ejemplo, entre otros, de las características de la narrativa de las vanguardias como género.

9 Todas las traducciones del inglés son mías.

${ }^{10}$ Bloch, Besse, y Jackson también han señalado la conexión entre la imagen vigente de Galvão y la estética de los antropófagos.
} 
Según los observadores de su época, Galvão aparentemente no sólo disfrutaba del papel de ícono de la novedad erótica y estética, sino que también conspiró en la creación de esta identidad. Reflexiones retrospectivas destacan su estudiada moda moderna, su maquillaje y vestuario exagerados, y su estilo chocante. " Galvão se valía de cualquier oportunidad para presentarse en su rol declamatorio, ante un público cautivo. Colaboró en su propia consagración como musa, además, con una pequeña colección de dibujos y versos entregada a Tarsila y compartida con los antropófagos. En este "Álbum de Pagú", que ostenta documentar su nacimiento, vida, pasión y muerte, Galvão se autorepresenta con una figura bailadora y trapecista que celebra su propia libertad de espíritu. El texto verbal que le acompaña describe a un ser natural y divino ("filha da lua ... filha do sol"), un ícono antropofágico ("Pagú era selvagem / inteligente / E besta"), y una fuente inspiradora de grandes alcances: "quero ir bem alto ... bem alto ... numa sensação de saborosa superioridade" (Campos).

Como he sugerido en otro contexto, sin embargo, es probable que esta autorepresentación contuviera una incipiente parodia del papel que ostentaba. ${ }^{12}$ Añadiría, además, que contiene el comienzo de una crítica más abierta precisamente de su papel de musa para los antropófagos. La singular interpretación de Galvão de este rol se destaca por una agresiva confrontación ante la mirada masculina, por ejemplo cuando respondía con irreverencia a los piropos que se le dirigían. Reportajes sobre sus declamaciones públicas dan testimonio de un estilo calculado y desviado de las convenciones vigentes de la recitación poética. En una de sus declamaciones, por cierto la más inolvidable, Galvão se vistió de una manera extravagante, y es de notar que su repertorio en esta auto-representación incorporara no sólo su propia poesía, sino también los versos de Bopp que la habían consagrado como musa. Las descripciones de este episodio insinúan una burla de su propio rol, en un agresivo strip-tease o flashing del público:

quando chegou a hora em que ia começar a declamação dela, ela foi até a frente do palco, e ela começou com um poema do Raul Bopp, que ... tem um estribilho até, "Eê Pagú, Eê Pagú". Então, quando chegava na hora do estribilho, ela corria até o fundo do palco e abria a capa, assim, de vermelho e preto, abria a capa e dizia "Eê Pagú". $\mathrm{E}$ os estudantes ficaram muito assustados, no princípio, e ouviram muito bem e bateram muita palma no fim (tomado de Campos 271).

Entre 1931 y 1933, esta crítica implícita del papel de musa se transforma en una sátira mordaz, periodística y novelesca, que desmitifica por completo su imagen previa. Durante marzo y abril de 1931, Galvão publica en la efimera revista $O$ Homem do Povo de Oswald una serie de comentarios teatrales y cinematográficos en la columna "A mulher do povo". Estos artículos desarrollan una crítica aguda de todos aquellos

\footnotetext{
11 Ver la compilación de testimonios en Campos.

${ }^{12}$ Ver la sección sobre Galvão en mi artículo "¿De quién es esta historia?: La narrativa de vanguardias en Latinoamérica".
} 
elementos de la educación femenina normalmente utilizados en la formación de la niña burguesa que iba a desempeñar su papel de Eva e, implícitamente, ser musa de algún poeta incipiente: el excesivo énfasis sobre el vestuario y maquillaje, la proyección de imágenes de Hollywood como modelos de femineidad, la recitación poética como arte de ostentación corporal y la hipocresía religiosa en el apoyo tácito del adiestramiento de las niñas para el amor. Se destaca en estos artículos la censura del inmoderado erotismo encarnado precisamente en la imagen de una musa moderna proyectada por Galvão entre los antropófagos. Según Galvão, varias instituciones - la familia, la iglesia, las escuelas normales y el círculo artístico- conspiraban en esta preparación de la mujer. ${ }^{13}$ Estos artículos, además, indagan sobre las prácticas culturales en que los literatos masculinos sirven de público inspirado frente a una declamadora femenina. Así Galvão embiste contra la argentina Berta Singerman, la alabada estrella de la recitación en esta época. Los performances líricos de Singerman sintetizaban una recitación casi cantada con gestos singulares. Declamaba ante vastos públicos en las Américas y Europa, y recibía los elogios hiperbólicos del mundo letrado masculino. ${ }^{14}$ Los innovadores culturales de las vanguardias solían describir a Singerman como una moderna musa inspiradora. ${ }^{15}$ Galvão, por su parte, caracterizó sus declamaciones como "scenarios de falsa arte moderna, umas coisas barrroco-futuristas cheias de douradinhos" (“As Óperas Faladas de Berta" 1).

Galvão desarrolló una crítica más compleja y más estrechamente ligada a su experiencia como musa de la antropofagia en la novela Parque Industrial (1933), obra a la vez radicalmente moderna en sus cuadros sinópticos de estilo fragmentado e izquierdista en su enfoque sobre las negativas consecuencias de la modernización en el distrito industrial de São Paulo. La crítica ha comentado el amplio retrato en esta obra de la sociedad paulista de la época y la explotación de los trabajadores de la industria textil. ${ }^{16}$ Sin entrar en un análisis detallado de la novela, cabe notar aquí que se enfoca principalmente sobre mundos femeninos (talleres de costura, escuelas normales, casas de parto, cárceles de mujeres y prostíbulos), o sobre otros mundos representados desde la perspectiva de alguna mujer. Entre sus docenas de personajes, la normalista Eleanora encarna la indagación de Galvão sobre la institución del círculo literario masculino que da entrada a una mujer como su mascota y fuente de inspiración. ${ }^{17}$ Aunque en Parque

\footnotetext{
${ }^{13}$ A despecho del carácter feminista de esta crítica, es de notar que Galvão tomara cierta distancia del feminismo burgués de su época, caracterizado por ella como superficial y políticamente ingenuo. Ver, por ejemplo, su artículo "Maltus Alem".

${ }^{14}$ Un artículo sobre Singerman, "La gran artista de la declamación Berta Singerman", publicada en 1927 en el Repertorio Americano, por ejemplo, presenta una colección de juicios críticos sobre su arte, que incluyen comentarios de Ramón del Valle Inclán, Manuel Machado, Juan Ramón Jiménez y Alejo Carpentier, entre otros.

${ }^{15}$ Ver, por ejemplo, el poema de Luis Quintanilla, "Toda ella".

16 Ver Besse, Bloch, Jackson y Unruh, “¿De quién es esta historia?”

${ }^{17}$ Jackson sugiere que Eleanora combina elementos de varias mujeres asociadas con Oswald de Andrade, Tarsila do Amaral y Patricia Galvão entre ellas (140).
} 
Industrial se divide la subjetividad entre varios personajes, Eleanora representa la fase como musa de la experiencia de Galvão, y, por medio de ella, la obra despoja la figura de la musa de su aura y poder de iluminación. Así en la novela esta mujer participa en "noites íntimas" con "o primeiro time" (grupo exclusivo, 15), es obligada a declamar en veladas (36), y queda "maravilhada" ante "tanta inteligência e tanta elegância" que la rodean en estas ocasiones artísticas (39). La novela, sin embargo, reduce el papel de la musa a la frivolidad de sus atavíos: Eleanora lleva piyamas al estilo de Berta Singerman o, en otra ocasión, una "fantasia cara de boneca Lenci" (43), y juega con su cachorro perfumado. Al dejarla por otra mujer, que encarna la fase política de la vida de Galvão, el poeta Alfredo observa que Eleanora se ha convertido en "o esboroamento da própria inteligência" y que "acreditou na comédia da alta roda"(90-91). Es de notar que la novela elija como el blanco de su sátira no sólo la musa en sí sino también la compleja práctica cultural que la construye. Así presenta varias escenas fragmentadas de soirées modernistas, pero revela, además, las condiciones sociales que implícitamente sostienen estos encuentros. En este ambiente, las mujeres pobres confeccionan los vestidos, las musas burguesas los ostentan y los poetas modernos, inspirados por la imagen visual de la Eva moderna, pero indiferentes al desigual tejido social de la modernización, cantan "como é lindo o teu tear!" (7).

La crítica cultural de Galvão ante las prácticas estéticas organizadas alrededor de una musa es directa, inequívoca y tenaz. A la vez, sin embargo, ella extrae de esta estética una de sus más efectivas estrategias narrativas en la novela Parque Industrial. Como he observado, en la estética de vanguardias, la musa femenina suele aparecer como un efecto de ostentación visual, corporalmente fragmentada con frecuencia por la mirada del poeta, como en los "olhos de faz doer" y el "corpinho de vai-e-vem" de la representación de Galvão por Bopp, o en la de Berta Singerman por el poeta estridentista Luis Quintanilla como un compendio de ojos, boca, manos, brazos, frente, y "alma cósmica" ("Toda ella" 50). Al emplear su denominado estilo fotográfico (Jackson 131), Galvão orienta esta estética hacia sus propios fines. Tal como los poetas que la observaban, privilegia lo visual, principalmente el cuerpo humano como predilecto objeto de representación, y redirige esta mirada del "extrañamiento"18 no solamente hacia las musas de la modernidad, sino hacia todos los niveles sociales; en particular, hacia los que sufren los efectos negativos de la modernización. Así, por ejemplo, retrata una mujer bella, pero pobre y encarcelada: "Os piolhos e pulgas se aninham no corpo delgado. A esteira suja, jogada num canto da prisão. $O$ brim azul da saia larga. As pernas bem feitas, descalças, morenas. Examina-as e cruza-as, arrastando, sexualizada, as unhas crescidas dos pés nas saliências da parede. Apalpa as carnes duras. Tão bonita, vae envelhecer sozinha, na prisão" (75).

La experiencia vital de Patrícia Galvão como musa voluntaria de los innovadores antropófagos provee la base de su propio proyecto: una revisión crítica de las prácticas

\footnotetext{
${ }^{18} \mathrm{Mi}$ empleo de este término incorpora tanto el concepto de ostranenie del formalismo como el Verfremdungseffekt brechtiano.
} 
culturales que eligen a ciertas mujeres como la inspiración de una nueva estética, y luego una indagación satírica sobre el tejido social en que surge el nuevo arte del modernismo brasileño. Este impulso crítico, que engloba desde las parodias de su autorepresentación como musa hasta la mirada fragmentada de su primera novela, constituye, además, el fundamento de su profesión de periodista en las décadas subsiguientes, como aguda comentarista cultural y promovedora en Brasil de un teatro innovador, abierto a las corrientes internacionales conscientemente críticas.

La posición crítica de Norah Lange ante su rol de musa de los martinfierristas es menos contenciosa con su medio que la de Galvão. Su relación con los innovadores artísticos es más duradera, y su carrera como escritora es, a la larga, algo más fructífera. ${ }^{19}$ Como Galvão, sin embargo, su contacto con los vanguardistas surge en la juventud, cuando éstos se reúnen semanalmente en las famosas tertulias de los años veinte, organizadas por la madre de Lange en la casa de la Calle Tronador. De estos encuentros iniciales, surgen paulatinamente su participación en las revistas, sus obras poéticas y sus primeras novelas, y su relación de compañera y esposa de Girondo. Como Galvão, Lange ha sido consagrada por la crítica en su rol: la "musa del ultraísmo" (de Miguel 103), "el ángel y la sirena" de los ultraístas (Sofovich 139), la "compañera" y "mascota" de los vanguardistas (Muschietti 91), la "salonnière" y "damisela" del grupo (Masiello 154), y "la musa e inspiración del grupo vanguardista Martín Fierro, una walkyria flaca y pelirroja" (Domínguez 44). ${ }^{20}$ Como en el caso de Galvão, además, los escritores de su época la denominaron una fuente de inspiración y la palpable personificación de la nueva estética del círculo. Nestor Ibarra declaró sobre la poesía de Lange en 1930 que "el ultraísmo necesitaba una mujer" (72), y Macedonio Fernández alabó su "grandeza sumisa" y su "voluntarioso espíritu en el arte" (tomado de Nóbile 15). Valentín Pedro la pintó como el espíritu corpóreo del nuevo arte: "Su alma se desnuda de todos los velos tradicionales y sus pies se libertan de todas las cadenas para danzar - cantar - magníficamente libre" (tomado de Lange, 45 dias; énfasis mio). En el prefacio a La calle de la tarde (1925), la primera colección poética de Lange, su amigo y admirador Borges establece un nexo metonímico entre la figura de la poeta y el ultraísmo. Inicialmente la enlaza al espacio geográfico (de su casa) en que surgieron los poetas: "Las noches y los días de Nora Lange son remansados y lucientes en una quinta que no demarcaré con mentirosa precisión topográfica" (5). ${ }^{21}$ Luego le atribuye los rasgos del verso ultraísta — "Leve y altiva y fervorosa como bandera que se realiza en el viento" (5) - e identifica su papel de

\footnotetext{
${ }^{19}$ Recientes análisis de la obra de Norah Lange incluyen la biografia de María Esther de Miguel y los estudios de Nora Domínguez, Naomi Lindstrom, Francine Masiello, Sylvia Molloy, Delfina Muschietti y Beatriz Sarlo.

${ }^{20}$ La representación de Sarlo es un poco distinta de la mayoría, en tanto destaca el carácter de "mujer-niña" que presentaba Lange entre los ultraístas y la índole familiar de su relación con ellos (70-83).

${ }^{21}$ Lange misma cambió la ortografía de su nombre de Nora a Norah.
} 
inspiradora de una fraternidad a la cual, por definición, no pertenece: "Ejercimos la imagen, la sentencia, el epíteto, rápidamente compendiosos. Y en esa iniciación advino a nuestra fraternidad Nora Lange y escuchamos sus versos, conmovedores como latidos, y vimos que su voz era semejante a un arco que lograba siempre la pieza y que la pieza era una estrella" (6). Finalmente, la invoca como su propia musa de la originalidad: "Quiero que mis palabras encareciéndola sean como las hogueras de cedro que alegraban en una fiesta bíblica las atentas colinas y que anunciaban la luna nueva a los hombres" (8).

En las metafóricas maniobras borgianas, el poeta toma posesión de la libertad que la mujer le inspira y, paradójicamente, la convierte en una entidad pasiva. Así las hojas de la revista Proa en que participaba, según Borges, "eran desplegables como ese espejo triple que hace movediza y variada la gracia inmóvil de la mujer que refleja" (6 énfasis mio). Como Galvão, no obstante, Lange abrazó su papel de musa, primero al construir su propia imagen como el punto de enfoque de la mirada masculina, y luego por vía de la nueva mujer en performance que representaba en sus extravagantes discursos - "macarrónicos", según Sylvia Molloy (At Face Value 127) - en las tertulias y banquetes de los ex-martinfierristas en los años treinta y cuarenta. Nora Domínguez ha propuesto una marcada división entre este papel público de Lange ante la ojeada masculina y su propio proyecto novelesco, en el cual deconstruye el carácter performativo de género sexual (44). Aunque concuerdo con Domínguez sobre la importancia de la performance en el proyecto de Lange, sin embargo, como Molloy, percibo una continuidad de estilo y de actitud crítica de vanguardias entre la actividad pública de Lange y su escritura. ${ }^{22}$ Es precisamente al abrazar el papel de musa e indagar sobre esta identidad que Lange desarrolla las estrategias de una estética propia que cuaja en sus obras en prosa a partir de Cuadernos de infancia (1937).

Esta negociación se despliega inicialmente en dos novelas tempranas, Voz de la vida (1927) y 45 dias y 30 marineros (1933) y en los discursos públicos reunidos bajo el título Estimados cóngeres. En su obra poética, como he notado, particularmente en La calle de la tarde, Lange repetidamente elabora su yo poético como la imagen reflejada en los ojos de un otro masculino: "Yo me he asomado / a las ventanas de tus ojos / y he visto tu alma / envuelta en mi imagen / como un niño" (27). En otro poema, se pincela claramente como la musa inspiradora de su destinatario vidente: “... por el caminito suave de sus miradas, llegué como una canción hasta su alma" (14). En la colección El rumbo de la rosa (1930), el enfoque cambia de miradas a voces, y un

${ }^{22}$ Mi diferencia con Domínguez radica en una distinta conceptualización de la noción de performance. Ella se basa principalmente en el nexo establecido por Judith Butler entre la performance y la construcción de la identidad, mientras que yo desarrollo un concepto de performance como un ensayo de ideas, una forma de indagación o pesquisa que, aunque no es ajena a la teoría de Butler, integra, además, investigaciones teóricas de Herbert Blau, Josette Féral y Barbara Freedman. Para una exposición más detallada sobre mi empleo del término, ver mi artículo "Una equívoca Eva moderna". 
poema, "Belleza que no te vieron", revela la problematización incipiente de una creatividad masculina estimulada por la belleza femenina: "Los hombres te miraron, y sonrieron / No tenías gracia, caminabas ligero. / No mirabas las vidrieras, como si ello / evitara recordar tu rostro feo" (El rumbo 71).

Con su primer experimento narrativo, Voz de la vida, Lange emprende una investigación estética más directa sobre el papel de musa. Esta obra epistolar de prosa lírica presenta la historia de Mila, quien le escribe cartas anhelantes a Sergio, su amado ausente. Al averiguar que Sergio es casado, busca la solución casándose con otro hombre, pero, al saber que Sergio la quiere, se fuga con él. Como Francine Masiello ha observado, la novela juega con las convenciones de las melodramáticas novelas semanales publicadas en revistas de los años veinte (155). Los críticos de la época elogiaron por una parte su presentación de una "voz de mujer" (tomado de Nóbile 78) ${ }^{23}$ y por otra criticaron la excesiva "masculinidad" de la protagonista Mila al hablar del amor (Doll 88, 90) ${ }^{24}$ Aunque el tono de reproche de esta aseveración seguramente manifiesta los prejuicios del momento ante la implícita afirmación rebelde del erotismo femenino, el crítico acierta al percibir un trastocamiento del orden literario. Invirtiendo las convenciones que la habían forjado como musa, Lange en esta obra construye una ausente y deseada musa masculina como fuente de inspiración para la creatividad femenina. En este sentido, se desprende en la novela cierto aire de familia con el Kunstlerroman de las vanguardias, por ejemplo Margarita de niebla de Jaime Torres Bodet o La casa de cartón de Martín Adán, en que un escritor o intelectual masculino se autoconcibe y se inspira a través de una imagen femenina.

En Voz de la vida, la protagonista evoca a Sergio como su fuente de inspiración - "Mi verso requiere tu nombre para ser fuerte" (38) - y son precisamente la ausencia e inaccesibilidad de éste las que estimulan la escritura de la mujer: "leo, escribo, y pienso, y así finaliza un día más, ausente de ti, doloroso de ti" (36). Para Mila, además, la evocación de Sergio como musa es consciente y voluntaria: “... paso las horas ... escribiéndote, pensándote" (25). Tal como Borges enlazó a Lange metonímicamente con un concreto espacio de la creación, una quinta en la "calle de la tarde" de su poemario, Mila liga a Sergio con las calles de la ciudad que éste ha caminado. Así se traslada ella al centro para mejor sentir su presencia e imaginarlo en su escritura, y, como Breton tras su Nadja en Paris, deambula por las calles bonaerenses en busca de su recuerdo. Una llamativa inversión de las convenciones de su época, sin embargo, surge al ponerse mayor énfasis en la voz que en el cuerpo de la musa masculina; Mila persigue el enigma de la palabra, no de la imagen, del hombre. No obstante el enfoque sobre el deseo, este trueque constituye por una parte una leve censura del excesivo erotismo que rodea la musa moderna, y en este sentido Lange coincide, aunque en tono

\footnotetext{
${ }^{23}$ De Nóbile reproduce la reseña de Fermín Estrella Gutiérrez, publicada en enero 1928 en la revista Nosotros de Buenos Aires.

${ }^{24}$ Esta crítica de Ramón Doll provee una de las bases para la propuesta de Francine Masiello que, ante las normas de historia y nación, Lange construye un proyecto de resistencia verbal.
} 
menor, con Galvão. Por otra parte, la inversión señala la búsqueda por Mila de un diálogo con su musa Sergio, pintado no sólo como el objeto de su deseo sino también como fuente de conocimiento: "¡Hermano! Maestro de la palabra intensa" (10). En contraste con la imagen paradójicamente inmóvil y apartada de la musa Norah invocada por Borges, Mila busca con Sergio el intercambio comunal: "La voz tuya, junto a la mía, sondeando cualquier tema, cualquier arte" (44). Se refuerza esta noción de diálogo con el cruce de fronteras entre espacios íntimos y públicos, entre la alcoba donde Mila escribe y las calles por las que divaga tras el recuerdo de Sergio que inspira su creación. Esta elisión entre mundos evoca, además, las maniobras de Norah Lange como emergente escritora que surge, como Galvão entre los antropófagos, en un ambiente de fraternidad literaria masculina.

Su segunda novela, 45 días y 30 marineros, agudiza esta negociación entre mundos y, tal como Parque Industrial de Galvão, emprende una indagación directa sobre el rol de una musa femenina. Esta obra narra las aventuras de Ingrid, única mujer en un barco de carga que cruza el Atlántico entre Buenos Aires y Oslo. La novela se enfoca concretamente en cómo esta mujer se maneja entre el peligro que representan los treinta marineros que quieren seducirla y las tentaciones de sus propios deseos eróticos. Tanto la crítica de la época como su biógrafa contemporánea leen esta obra principalmente como fuente verídica de información sobre el viaje en 1927 de Lange a Noruega, país de origen de su padre. Tomando en cuenta que se publicó en 1933, sin embargo, época en que Lange participaba plenamente en las tertulias y banquetes de los innovadores literarios bonaerenses, creo que la novela alegoriza sus propias maniobras como una mujer, a veces solitaria, en un ámbito cultural de hombres. Dos acontecimientos proveen el contexto para esta lectura, biográfica a su modo. Para la presentación del libro, ocasión grabada en fotografia, el grupo de escritores con quienes Lange se asociaba se disfrazó de marinero, con Oliverio Girondo de capitán y Lange, en el centro, en traje de sirena. En 1936, para celebrar a Girondo en la ocasión del "bautismo de su bergantín 'Martín Fierro", Lange elaboró en su discurso una extendida metáfora marítima para caracterizar al grupo, denominando a su público de letrados masculinos los "tripulantes, grumetes, y náufragos", a Girondo como el Almirante, y a ella misma como la madrina de la embarcación (Estimados cóngeres 2629).

Desde la escena inicial de la novela, la protagonista Ingrid, quien, como Lange ante la mirada de Borges, "parece una walkyria" (45 días y 30 marineros 26 ), ${ }^{25}$ toma conciencia de su aspecto de imagen para los que la rodean: "Al subir a bordo, una multitud de miradas celestes le corretea las piernas" (5). En su primer encuentro con

\footnotetext{
${ }^{25}$ Tanto algunos críticos de la época como unos más recientes emplean la palabra walkyria para caracterizar a Norah Lange. Al señalar su "raigambre noruega" y comparar las imágenes evocadas por sus versos con la prosa de "los escaldas remotos que apodaban a los navíos potros del mar y a la sangre, agua de la espada", y al destacar la belleza inspiradora de Lange, Borges fue probablemente el primero en construir esta identidad walkyriana ("Prólogo" 7).
} 
el grupo, toma su designado papel de la mujer en performance: "Irrumpe sobre ella la convicción de su rol cordial y se deja llevar por las voces de los hombres, que la reconocen desde ya, ubicada totalmente en su destino de mujer" (13). En este momento, se sube a una litera y comienza a bailar a un ritmo del jazz, generando así un intercambio de relatos y brindis entre los hombres que la rodean. Esta escena y otras semejantes, en que Ingrid baila un tango o pronuncia un discurso, evocan la imagen de Lange desempeñando su performance ante los ex-martinfierristas. La novela simultáneamente celebra este papel y presenta la crónica de las maniobras de Ingrid con el rol. Ante la conciencia de ser incesantemente observada, por ejemplo, y tal como hace Mila con su musa Sergio, Ingrid invierte el proceso; concretándose como esmerada observadora, recorre con sus miradas de extrañamiento (análogas a las de Galvão en Parque Industrial) las fachadas masculinas a su alcance: el capitán "ya no tan inédito para su retina" que "ofrece los contornos usuales de todos los hombres noruegos que llegan a los cuarenta y cinco años", y los demás, que "no la conducen a hondas reflexiones indagatorias de belleza masculina" ni ofrecen "un exterior perdurable para el recuerdo" (10-11).

Observaciones como éstas integran un proceso de aprendizaje para la protagonista, cuyo papel se despliega en la de un etnográfico observador-participante que se fascina ante esta cultura masculina y la estudia minuciosamente. En este encuentro, Ingrid inicialmente ejecuta un papel comparable al de Lange en los banquetes martinfierristas: “... lanza un caudal de palabras para diseminar ese ambiente estirado que reina al principio de la comida. ... en diez minutos todos los hombres se sienten tan cómodos como cuando relatan anécdotas, subidas de tono, en las cubiertas oscuras" (100, énfasis mío). En el ambiente más relajado, Ingrid, a la vez que baila, observa cuidadosamente lo que hacen los hombres: "Los marineros bailan al compás de una música compuesta por ellos. Sus siluetas, lanzadas al aire, retorcidas, adquieren un aspecto fantástico en la noche iluminada por reflectores. La luz horizontal de las lámparas los corta por la mitad, desparramándoles los contornos en una lenta confusión. ... los hombres se mueven entre los triángulos de sombra, y aparecen, sigilosamente, como accionados por una fuerza extraña" (102-103).

Esta decodificación del mundo masculino forma la base del emergente proyecto de la protagonista Ingrid para definir su propio papel. Consciente al instante de su rol como imagen del deseo masculino, como he notado, también observa desde el inicio del viaje que todos, menos ella, tienen una designada tarea en el trabajo cotidiano del viaje marítimo. Con la sugestiva excepción de un intelectual masculino con quien dialoga de cuando en cuando, ella es la única pasajera o turista en este barco de carga. La organización de los espacios novelescos refuerza esta singular situación, ya que la negociación de la protagonista de un papel viable se desenvuelve con cierta fluidez entre el íntimo ámbito del camarote y los espacios más públicos del barco y de los puertos en que hacen escala. Inicialmente lee y escribe en su camarote, y realiza sus performances de baile y discurso, por otra parte, en los espacios más abiertos. Estas divisiones se ofuscan, sin embargo, con las actividades de la protagonista. Por un lado, 
la entrada, de cuando en cuando, de varios hombres al camarote provoca el desarrollo de escenas de fracasada seducción melodramáticamente (de)construidas por la protagonista como parte de su examen del mundo masculino y las relaciones entre los sexos. A la vez, Ingrid paulatinamente intercala su propia actividad más intelectual y privada en su emergente papel público. Así, comienza a leer en la cubierta, en parte como una defensa ante los avances masculinos, en parte como punto de partida para un diálogo con ellos, particularmente con el intelectual que comparte sus lecturas. A base de sus superiores conocimientos lingüísticos, además, asume en el multilingüe mundo del barco y los puertos una identidad pública de maestra informal de lenguas y traductora, actividades nítidamente ligadas a su etnográfica posición de observadora-participante. Al elaborar este rol propio, entonces, Ingrid se maneja entre un abigarrado mundo público del quehacer masculino y su propia situación como mujer solitaria que carece de una clara vocación en este mundo de hombres. Es de notar que, para Ingrid, la construcción de este rol surja precisamente de su asignado papel como imagen-musa y que, en base da esa experiencia, desarrolla su agudeza analítica como observadora y su destreza de traductora entre mundos.

Esta identidad de perspicaz observadora-participante, que de cuando en cuando se instala en el centro de la escena con una performance ante la mirada masculina, encarna la estrategia de Lange en sus discursos celebradores ante los contertulianos bonaerenses de los años treinta y cuarenta. Estas ocasiones poseen el aire satírico de las declamaciones de Galvão. Según Lange, ella decía estos discursos "subida en un cajón de vino porque me gustaba dominar la 'multitud"' (tomado de Nóbile 20), actividad que, como bien señala Molloy, hacía eco de los discursos de su adolescencia ejecutados para los vecinos desde el techo de su casa. ${ }^{26}$ Como Galvão en "A mulher do povo", en uno de sus discursos, Lange abiertamente embiste los papeles performativos de mujeres burguesas, "conferencias, recitales, conciertos a dos pianos ... y otras lamentables efervescencias" (Estimados cóngeres 46). Su confesado afán por "dominar la multitud", sin embargo, señala una consciente apropiación del denominado rol de musa para encaminarlo hacia sus propias metas de desarrollar una posición viable en la vida cultural pública y de realizar un proyecto estético novelesco.

A primera vista, la hiperbólica y exuberante proliferación de la palabra en los discursos de Lange parece ser antagónica al estilo escueto y pulido de sus obras en prosa de mayor éxito: el autobiográfico Cuadernos de infancia (1937) y Antes que mueran (1944), Personas en la sala (1950), y Los dos retratos (1956). Sin embargo, la estrategia principal en estas "anatomías" (como ella las llamaba) de personas celebradas provee el fundamento del estilo fragmentado y la mirada de extrañamiento que marcan su singular modo de caracterizar los personajes en la prosa. Los discursos son literal y figuradamente "anatómicos". Con su mirada irreverente y escéptica hacia la

${ }^{26}$ Lange describe estas actividades detalladamente en sus memorias de la juventud, Cuadernos de infancia (276-78). Molloy observa: "This ritualistic performance ... surely prefigures the adult Lange's nonsensical discursos" (At Face Value 135). 
actividad intelectual y cultural de los coetáneos, los discursos de Lange poseen el aire de sátira y ciertos rasgos de la anatomía literaria clásica: la caracterización estilizada de personajes, el enfoque sobre actitudes y orientaciones mentales, la exuberante acumulación enciclopédica de detalles para asaltar al objeto de la anatomía con su propia jerga, la ostentada erudición del satírico, y la tendencia digresiva en la exposición. ${ }^{27}$ Como el anatomista, además, Lange dirige en sus discursos una mirada clínica sobre algún detalle físico (el ombligo, la epidermis) o psicológico (la haraganería, la afición a la comida exótica o la bebida) como la base de una indagación profunda sobre un personaje. En un discurso, Lange describe el proceso anatómico, ligándolo con la práctica literaria: "Etimológicamente, la anatomía implica el demorado entusiasmo de separar, por medio de instrumento - y no por mera distracción, las diversas partes que componen un ser despierto, con el ambiguo prurito de husmear su a veces desordenada distribución. La literatura, o disección, puede constituir ese instrumento que separe, con puntiaguda vehemencia, la porción más desnivelada del escritor o poeta ... (39). Una caracterización suya de Girondo, ejemplifica el proceso: "Después de detenerme, devotamente, en su sistema circulatorio, en su pie perfecto que suele exhibir durante excursiones fluviales o en noches pobladas de imprecisiones literarias, en su dedo meñique y mediterráneo que no tolera retoques; ... estremecióme súbita intuición femenina: Oliverio Girondo, electro-dinámico" (Estimados cóngeres 67).

En las obras en prosa, con un estilo depurado de la verbosidad, esta mirada excéntrica y digresiva provee el fundamento de la construcción del personaje langeano, una proyección de la subjetividad autorial en las excentricidades - física o psicológicamente anatómicas - de sus ficticias construcciones humanas. Unos muy citados fragmentos de Cuadernos de infancia describen, en los términos literales y concretos de una niña, esta anatómica proyección de una autora en sus personajes:

\begin{abstract}
Desde muy pequeña me gustaba mirar con mucho detenimiento a la gente. ... Al clavar los ojos en las personas que venían a vernos ... me imaginaba su perfil por dentro. Era como si me introdujera en la persona, físicamente, pero sólo en la cara. ... Una tarde ... quise introducirme en la cara de cierta persona para formarle las facciones con mi cuerpo. Tuve que construir muchas figuras imaginarias, muchos brazos caídos, muchas piernas enredadas (35-37).
\end{abstract}

La estrategia aquí descrita se asemeja a lo que Lange llamó "auscultación" visual en sus discursos (Estimados cóngeres 21 ) ${ }^{28}$ y se destaca por la confesada afición de la autora al espionaje, o a lo que Molloy, citando a Felisberto Hernández, llama "la lujuria de ver" ("the lust for looking". At Face Value 130). También se destaca esta

\footnotetext{
${ }^{27}$ Mi fuente para esta caracterización de la "anatomía" literaria es la conocida exposición de Northrop Frye sobre el asunto (308-312).

${ }^{28}$ Al emplear la palabra “auscultación", Lange destaca el empleo tanto de la visión como del oído en el proceso de análisis anatómico.
} 
estrategia por la derivación de una maniobra verbal y narrativa del contexto corporal y performativo del papel de musa. Es precisamente esta identidad de musa moderna - mujer elevada ante un público vidente enfocado en su performance - la que le proporciona a Lange la alta conciencia de lo corporal y la necesaria distancia para esta penetrante mirada de la "auscultación", análoga a la de Galvão en Parque Industrial, y el resultante análisis anatómico, excéntrico, distanciado, irónico y, a veces, satírico, de sus personajes.

En un período de transformaciones sociales para las mujeres, Patrícia Galvão y Norah Lange realizaron complejos papeles en los ámbitos culturales de São Paulo y Buenos Aires. Como musas de sus círculos literarios, asumieron un rol de despliegue erótico-visual para servir de fuentes inspiradoras para la innovación estética masculina, práctica que aparentemente reforzaba las divisiones tradicionales de género sexual. $\mathrm{Al}$ interpretar el papel de la imaginada Eva moderna, sin embargo, ejecutaron impresionantes maniobras. Inicialmente, las dos emplearon la caracterización asignada para negociar una posición viable en mundos culturales habitados principalmente por hombres. Conscientes de la problemática implícita en su posición, las dos elaboraron una indagación crítica sobre el rol de musas y sobre las prácticas sociales y culturales de las cuales surgía esta identidad femenina. Con notable agilidad, las dos transfiguraron sus palpables experiencias como musas en las posturas críticas y los procedimientos estéticos de sus contribuciones inéditas y duraderas a una compleja y crucial época de la vida cultural latinoamericana.

\section{Obras CITADAS y CONSUlTADAS}

Benjamin, Walter. "The Work of Art in the Age of Mechanical Reproduction". Illuminations. Hannah Arendt, ed. Harry Zohn, trad. Nueva York: Shocken, 1969. 217-51.

Besse, Susan. "Pagú: Patrícia Galvão-Rebel". The Human Condition in Latin America. William H. Beezley y Judith Ewell, eds. Wilmington, Delaware: Scholarly Resources, 1987. 103-117.

Blau, Herbert. Blooded Thought: Occasions of Theatre. Nueva York: PAJ, 1982. To All Appearances: Ideology and Performance. Nueva York: Routledge, 1992.

Bloch, Jayne. "Patrícia Galvão: The Struggle Against Conformity". Latin American Literary Review 14:27 (1986): 188-201.

Borges, Jorge Luis. "Prólogo". La calle de la tarde. Por Norah Lange. Buenos Aires: J. Samet, 1925. 5-8.

Butler, Judith. Gender Trouble: Feminism and the Subversion of Identity. Nueva York: Routledge, 1990.

"Performative Acts and Gender Constitution: An Essay in Phenomenology and Feminist Theory". Performing Feminisms: Feminist Critical Theory and Theatre. Sue-Ellen Case, ed. Baltimore: Johns Hopkins. 270-82. 
Campos, Augusto de. Pagú-Vida-Obra. São Paulo: Brasiliense, 1982.

Caws, Mary Ann. "Ladies Shot and Painted: Female Embodiment in Surrealist Art".

The Female Body in Western Culture: Contemporary Perspectives. Susan Rubin

Suleiman, ed. Cambridge: Harvard University Press, 1986. 262-87.

Caws, Mary Ann, Rudolf Kuenzli y Gwen Raaberg, eds. Surrealism and Women. Cambridge: MIT Press, 1991.

Díaz Arciniega, Víctor. Querella por la cultura "revolucionaria" (1925). México, DF: Fondo de Cultura Económica, 1989.

Doll, Ramón. "Literatura Femenina". Nosotros 22:230 (julio 1928): 88, 90.

Domínguez, Nora. "Literary Construction and Gender Performance in the Novels of Norah Lange". Latin American Women's Writing: Feminist Readings in Theory and Crisis. Anny Brooksbank Jones y Catherine Davies, eds. Oxford: Clarendon, 1996. 30-45.

Féral, Josette. "Performance and Theatricality". Modern Drama 25 (1982): 170-84. Forster, Merlin. "Toward a Synthesis of Latin American Vanguardism”. Vanguardism in Latin American Literature: An Annotated Bibliographical Guide. Merlin H.

Forster y K. David Jackson, comps. Nueva York: Greenwood, 1990. 1-11.

Freedman, Barbara. "Frame-Up: Feminism, Psychoanalysis, Theatre". Performing Feminisms: Feminist Critical Theory and Theatre. Sue-Ellen Case, ed. Baltimore: Johns Hopkins, 1990. 54-76.

Frye, Northrop. Anatomy of Criticism: Four Essays. Princeton: Princeton University Press, 1971.

Galvão, Patrícia. "Maltus Alem". O Homem do Povo 1 (27 de marzo, 1931): 2.

"As Operas Faladas de Berta". O Homem do Povo 1 (27 de marzo, 1931): 4. Parque Industrial. São Paulo: Alternativa, 1981.

"La gran artista de la declamación Berta Singerman, que en marzo próximo llegará a Costa Rica: Extractos de juicios críticos”. Repertorio Americano 14.8 (26 de febrero, 1927): 120, 122.

Ibarra, Néstor. La nueva poesía argentina: Ensayo crítico sobre el ultraísmo, 19211929. Buenos Aires: de Molinari, 1930.

Jackson, K. David. “Afterword”. Industrial Park. Elizabeth Jackson y K. David Jackson, ed y trad. Lincoln: University of Nebraska Press, 1993. 115-153.

Lange, Norah. Antes que mueran. Buenos Aires: Losada, 1944.

La calle de la tarde. Buenos Aires: J. Samet, 1925. Cuadernos de infancia. Buenos Aires: Domingo Viau, 1937. 45 dias y 30 marineros. Buenos Aires: Tor, 1933. Los días y las noches. Buenos Aires: El Inca, 1926. Los dos retratos. Buenos Aires: Losada, 1956. Estimados cóngeres. Buenos Aires: Losada, 1968. Personas en la sala. Buenos Aires: Centro Editor de América Latina, 1981. El rumbo de la rosa. Buenos Aires: Proa, 1930. Voz de la vida. Buenos Aires: Proa, 1927. 
Lindstrom, Naomi. "Norah Lange: Presencia desmonumentalizadora y femenina en la vanguardia argentina". Crítica Hispánica 5.2 (1983): 131-48.

Masiello, Francine. Between Civilization \& Barbarism: Women, Nation, and Literary Culture in Modern Argentina. Lincoln: University of Nebraska Press, 1992.

Miguel, María Esther de. Norah Lange: Una biografia. Buenos Aires: Planeta, 1991. Molloy, Sylvia. At Face Value: Autobiographical Writing in Spanish America. Cambridge: Cambridge University Press, 1991.

"Dos proyectos de vida: Cuadernos de infancia de Norah Lange y El archipiélago de Victoria Ocampo". Filología 20.2 (1985): 279-93.

Müller-Bergh, Klaus. "El hombre y la técnica: Contribución al conocimiento de corrientes vanguardistas hispanoamericanas". Philologica Hispaniensia in Honorem Manuel Alvar. Tomo 4. Madrid: Gredos, 1983. 279-302.

Muschietti, Delfina. "Las mujeres que escriben: Aquel reino anhelado, el reino del amor". Nuevo Texto Crítico 2.4 (1989): 79-102.

Nóbile, Beatriz de. Palabras con Norah Lange. Buenos Aires: Carlos Pérez, 1968. Picchia, Paulo Menotti del. "Arte Moderna". Vanguarda Européia e Modernismo Brasileiro. Gilberto Mendonça Teles, ed. Rio de Janeiro: Vozes, 1976. 287-93. Quintanilla, Luis. “Toda ella”. El Universal Ilustrado 10.509 (10 de febrero, 1928): 50.

Sarlo, Beatriz. Una modernidad periférica: Buenos Aires 1920 y 1930. Buenos Aires: Nueva Visión, 1988.

Schwartz, Jorge. Vanguardas Latino-Americanas: Polêmicas, manifestos e textos críticos. São Paulo: USP, 1995.

Sofovich de Gómez de la Serna, Luisa. "Retrato con pelo dorado". Páginas escogidas de Norah Lange. Beatriz de Nóbile, ed. Buenos Aires: Kapelusz, 1972. 136-48.

Teixeira Furlani, Lúcia Maria. Patrícia Galvão: Livre na imaginação, no espaço e no tempo. Santos: UNICEB, 1989.

Unruh, Vicky. “¿De quién es esta historia?: La narrativa de vanguardias en Latinoamérica". De próxima aparición en De la convergencia de literatura y artes a la práctica artística de la vida. Las vanguardias a principios de siglo en el Mundo Ibérico. Harald Wentzlaff-Eggebert, ed. Frankfurt: Vervuert, 1997. "Una equívoca Eva moderna: Performance y pesquisa en el proyecto cultural de Antonieta Rivas Mercado". De próxima aparición en Revista de Crítica Literaria Latinoamericana. 1997.

Latin American Vanguards: The Art of Contentious Encounters. Berkeley: University of California Press, 1994.

Vela, Arqueles. El café de nadie. Un crimen provisional. La Señorita Etc. México, DF: Lecturas Mexicanas, 1990. 